\title{
Envolvimento parental, competência social e o desempenho acadêmico de escolares
}

\author{
Parental involvement, social ability and academic performance of students
}

\author{
Aline Costa Fantinato ${ }^{[a]}$, Fabiana $\mathrm{Cia}^{[\mathrm{b}]}$ \\ [a] Psicóloga graduada pelo Centro Universitário Hermínio Ometto, Pirassununga, SP - Brasil, e-mail: alinefantinato@hotmail.com \\ [b] Professora associada do curso de Psicologia do Centro Universitário Hermínio Ometto, Pirassununga, SP - Brasil, e-mail: \\ fabianacia@hotmail.com
}

\section{Resumo}

Este estudo teve como objetivos comparar a frequência de envolvimento parental, entre pais e mães, e investigar a relação entre a frequência de envolvimento parental, a competência social e o desempenho acadêmico de crianças escolares. Participaram do estudo 12 casais, sendo eles pais de alunos de $2^{a}$ série do ensino fundamental, e três professoras dessas crianças. Os casais preencheram o questionário "Avaliação do envolvimento parental" e, para avaliar o repertório de habilidades sociais, os problemas de comportamento e o desempenho acadêmico das crianças, as professoras responderam ao Social Skills Rating System (SSRS - Versão para professores). Foram efetuadas análises estatísticas descritivas, teste-t e de correlação de Pearson. Cinco dos 41 itens avaliados sobre o envolvimento parental as mães realizavam mais frequentemente que os pais. Quanto maior a frequência da participação dos pais nas atividades escolares, culturais e de lazer dos filhos, maior o desempenho acadêmico das crianças. A frequência da participação das mães nas atividades escolares, culturais e de lazer dos filhos estava negativamente correlacionada com o índice de problemas de comportamento externalizantes e positivamente correlacionada com o repertório de habilidades sociais das crianças. Por fim, a comunicação entre mãe e filho estava positivamente correlacionada com o repertório de habilidades sociais das crianças.

Palavras-chave: Envolvimento parental. Problemas de comportamento. Habilidades sociais. Desempenho acadêmico.

\section{Abstract}

This study aimed to compare the frequency of parental involvement among fathers and mothers and investigate the relationship between the frequency of parental involvement, social competence and academic performance of 
schoolchildren. The study included 12 couples who were parents of students in second grade of elementary school and three teachers of these students. Both parents filled out a questionnaire "Parental Involvement Evaluation" and to evaluate children's social skills repertoire, behavior problems and academic performance, the teachers responded to the Social Skills Rating System (SSRS - Version for teachers). Were performed descriptive statistics analysis, t-test and Pearson correlation. Five of the 41 items evaluated about parental involvement, mothers realize more often than fathers. Higher the frequency of father participation in children's school activities, cultural and leisure activities, greater the children's academic performance. The frequency of mothers' participation in children's school activities, cultural and leisure activities was negatively correlated with the rate of externalizing behavior problems and positively correlated with the children's social skills repertoire. Finally, the communication between mother and child were positively correlated with the children's social skills repertoire.

Keywords: Parental involvement. Behavior problems. Social skills. Academic performance.

O presente estudo aborda a temática do impacto do envolvimento parental sobre a competência social e o desempenho acadêmico de crianças escolares, considerando dois referenciais teóricos: Treinamento de Habilidades Sociais e Psicologia do Desenvolvimento Infantil. A importância de identificar a relação dessas variáveis decorre do aumento crescente de crianças sendo encaminhadas para classes ou escolas especiais, não por ter uma excepcionalidade óbvia, mas por apresentar problemas de comportamento e/ou baixo desempenho acadêmico. Sendo assim, torna-se relevante investigar uma das facetas que influenciam o comportamento e o desempenho acadêmico das crianças, como, por exemplo, o envolvimento parental. A presente revisão bibliográfica abordará os seguintes tópicos:

1) as habilidades sociais na infância: um enfoque no contexto escolar;

2) aimportância do envolvimento parental sobre a competência social e o desempenho acadêmico dos filhos;

3) a necessidade de estudos brasileiros sobre a relação entre envolvimento parental, competência social e desempenho acadêmico das crianças.

\section{Habilidades sociais na infância}

De acordo com Del Prette e Del Prette (2005), as habilidades sociais são as distintas classes de comportamentos sociais do sujeito, que colaboram para a competência social, sendo esta entendida como a capacidade do indivíduo articular fatores pessoais, culturais e situacionais para alcançar determinado objetivo, sem se prejudicar e prejudicar o outro, sendo necessário também apresentar um repertório de habilidades sociais elaborado. Além desses conceitos, tem-se ainda o de desempenho social, que é qualquer comportamento emitido na relação com o outro.

O indivíduo começa a desenvolver seu repertório de habilidades sociais já na infância, sendo que os efeitos de um repertório de habilidades sociais bem elaborado não contribuem somente para relações harmoniosas nessa fase, mas também aumentam a capacidade de resolução de problemas e enfrentamento de situações desagradáveis e estressantes, preparando a criança para a vida adulta (Del Prette \& Del Prette, 2005).

Além disso, dados da literatura apontam para uma relação positiva entre desenvolvimento social e desempenho acadêmico. Por exemplo, Del Prette e Del Prette (2005) apontam que a maioria das crianças com problemas de aprendizagem é avaliada negativamente em sua competência social, tanto por colegas quanto por professores e pais. Os professores relatam que essas crianças são mais agressivas, imaturas, mais dependentes e apresentam dificuldade em unir-se a um grupo de atividade. Já para os pais, essas crianças apresentamimpulsividade, baixo autocontrole, ansiedade, dispersão e déficits em habilidades verbais. Tanto as crianças que apresentam problemas internalizantes quanto as que apresentam problemas externalizantes são tratadas de maneira diferenciada pelos colegas, o que pode causar efeitos negativos sobre o funcionamento psicológico.

O estudo realizado por Bandeira, Rocha, Souza, Del Prette e Del Prette (2006) mostra a relação entre comportamentos problemáticos, habilidades sociais e desempenho acadêmico. Participaram do estudo 257 crianças de ambos os sexos, com idade 
média de 8 anos, que cursavam entre a $1^{\mathrm{a}}$ e a $4^{\mathrm{a}}$ séries do ensino fundamental de duas escolas públicas e uma particular, e seus pais e professores. Primeiramente, os professores classificaram os alunos em relação à apresentação de comportamentos problemáticos, sendo que, segundo essa classificação, aproximadamente $84 \%$ das crianças não apresentavam nenhum tipo de comportamento problemático, 9,4\% emitiam poucos comportamentos problemáticos e cerca de 7\% foram classificadas como apresentando muitos comportamentos problemáticos. Foi feita também uma avaliação para verificar a emissão de comportamentos problemáticos de acordo com o nível socioeconômico da família. Verificou-se que crianças pertencentes a famílias com menor poder aquisitivo apresentaram mais comportamentos problemáticos do que crianças com alto poder aquisitivo. $\mathrm{Na}$ avaliação de pais e professores sobre habilidades sociais, nota-se que, quanto maior o repertório de habilidades sociais da criança, menor a ocorrência de comportamentos problemáticos. Os professores avaliaram também os comportamentos problemáticos em relação à competência acadêmica, mostrando que, quanto maior o grau de competência acadêmica, menor a ocorrência de comportamentos problemáticos.

De fato, crianças com baixo desempenho escolar podem associar isso à incompetência pessoal, gerando sentimentos de vergonha, baixa autoestima e alienação em relação à aprendizagem, como também manifestações externalizadas, a exemplo de sentimentos de raiva e hostilidade para com os outros (Marturano \& Loureiro, 2003).

Um dos fatores apontados na literatura como influenciador do comportamento e do desempenho acadêmico das crianças é a qualidade do relacionamento entre pais e filhos. Ressalta-se que este estudo será exploratório e com delineamento correlacional, dada a importância da identificação de possíveis relações entre as variáveis estudadas, para que posteriormente possa embasar trabalhos interventivos (Cozby, 2006).

\section{Importância do papel parental e do contexto escolar para o desenvolvimento infantil}

Os fatores ambientais influenciam o processo de aprendizagem das habilidades sociais, levando em consideração que as crianças aprendem por observação/modelação, instrução e consequenciação (Del Prette \& Del Prette, 2005). É por meio das relações parentais que se dá a transmissão da cultura, ou seja, os valores e normas da família e da cultura em que estão inseridos (Szelbracikowski \& Dessen, 2007).

A função dos pais na aprendizagem interpessoal da criança depende da maneira como eles lidam com a educação de seus filhos. A monitoria positiva e o comportamento moral se encontram dentro das práticas educativas parentais positivas, enquanto que as práticas de abuso físico ou psicológico, como também o controle aversivo e negligência são consideradas práticas negativas (Del Prette \& Del Prette, 2005).

A fim de exemplificar a importância das práticas e do envolvimento parental para o desenvolvimento infantil, tem-se o trabalho realizado por Cia, Pamplin e Del Prette (2006), que teve por objetivos comparar indicadores de envolvimento de ambos os pais com seus filhos e verificar a relação entre envolvimento dos pais sobre o repertório de habilidades sociais e os problemas de comportamento internalizantes e externalizantes das crianças. Participaram deste estudo 110 crianças da $4^{a}$ série do ensino fundamental, com idade entre 9 e 12 anos. Verificou-se que, na opinião das crianças, as mães tinham uma frequência maior que os pais no que se refere à comunicação e à participação em atividades de higiene e alimentação dos filhos. Quanto à participação dos pais na vida escolar dos filhos e nas atividades culturais e de lazer, os resultados não mostraram nenhuma diferença estatisticamente significativa entre pais e mães. Esses quesitos avaliados estiveram correlacionados positivamente com os escores de habilidades sociais e negativamente correlacionados com os de problemas de comportamentos externalizantes das crianças.

Para desdobrar alguns comportamentos de ambos os pais, que levam a resultados negativos por parte dos seus filhos, Lindsey, Caldera e Lankersley (2009) verificaram a relação entre a segurança no relacionamento entre pais e filhos, a reciprocidade positiva e negativa na relação entre pais e filhos - como possíveis mediadores e moderadores da relação entre conflitos parentais e o relacionamento das crianças com seus pares. Oitenta pais/mães e crianças de 15 a 18 meses foram observadas. Em sequência, as crianças foram observadas interagindo com os colegas, quando tinham 36 meses de idade. Os resultados apontaram 
que os conflitos parentais estavam positivamente correlacionados com comportamentos negativos da interação das crianças com seus pares. No entanto, apesar da existência de conflitos conjugais, os comportamentos positivos da interação entre as crianças e seus pares foram mediados pela segurança no relacionamento mãe-filho e pela reciprocidade emocional materna. Em contrapartida, a reciprocidade emocional paterna influenciou os efeitos negativos dos conflitos conjugais sobre os comportamentos da criança com seus pares. A relação entre conflitos conjugais e os comportamentos negativos da interação entre as crianças e seus pares foi mediada pela reciprocidade emocional materna e pela segurança do relacionamento paterno. Os autores concluíram que a segurança no relacionamento e a reciprocidade emocional entre pais e filhos tornaram-se um moderador importante na relação entre conflitos conjugais e no relacionamento das crianças com seus pares.

Dados da literatura internacional também mostram a relação entre alguns comportamentos parentais e os problemas de comportamento dos filhos. Por exemplo, um pai que não se interessa pelas atividades do filho (Anselmi, Piccinini, Barros \& Lopes, 2004; Coley, Morris \& Hernandez, 2004; Carlson, 2006), que é negligente e/ou utiliza práticas educativas punitivas e autoritárias para com seu filho (MacKinnon-Lewis, Castellino, Brody \& Fincham, 2001) e que não oferece suporte emocional e afeto ao filho (Davidov \& Grusec, 2006; Newman, Harrison, Dashiff \& Davies, 2008) tem sido identificado como fator de risco para o aparecimento de problemas de comportamento internalizantes e externalizantes nas crianças, tanto no ambiente escolar quanto no ambiente familiar (Dunn, 2004; Lansdorf, Criss, Pettit, Dodge \& Bates, 2003; Patterson, Mockford \& Stewart-Brow, 2005).

\section{Necessidade de estudos brasileiros sobre a relaçáo entre competência social, desempenho acadêmico e envolvimento parental}

As práticas educativas dos pais para com seus filhos estão num processo de transformação, passando de uma postura de rigidez para uma de maior permissividade. Essa mudança acarretou problemas na interação entre pais e filhos, pois muitos pais se sentem confusos sobre como devem educar sua prole (Bolsoni-Silva, Del Prette \& Del Prette,
2000). Tal fator fica mais marcante considerando que as mudanças nas práticas parentais ocorreram concomitantes às mudanças na estrutura familiar, pois com a entrada da mulher no mercado de trabalho os homens passaram a assumir maior responsabilidade por tarefas nos cuidados e na educação dos filhos, e as mulheres passaram a dividir essas tarefas com seus esposos (Bertolini, 2002; Brandth \& Kvande, 2002; Cabrera, Tamis-Lemonda, Bradley, Hofferth \& Lamb, 2000; Diniz, 2004). Além disso, várias pesquisas realizadas no contexto brasileiro apontam para a importância do pai em diversas áreas do desenvolvimento infantil (Cia, D'Affonseca \& Barham, 2004; Cia, Williams \& Aiello, 2005; Cia, Pamplin e Del Prette, 2006).

Soma-se a tudo isso o fato de que aumenta cada vez mais o número de alunos que estão sendo classificados com necessidades educacionais especiais, que não apresentam uma deficiência orgânica, mas que têm histórico de fracasso escolar e dificuldades de aprendizagem, normalmente acompanhados de problemas de comportamento (Pamplin, 2005). Normalmente esses alunos encontram-se na $1^{\mathrm{a}}$ ou $2^{\mathrm{a}}$ série do ensino fundamental. Essas séries são consideradas como uma fase de transição, em que as crianças têm que se adequar às normas da escola e se relacionar de outra maneira com as diferentes regras sociais impostas pelos seus pares (Marturano, 2004, 2008).

Considerando a existência de poucos estudos no contexto brasileiro que comparam o envolvimento parental entre pais e mães de crianças no início da escolarização, e relacionam esse envolvimento com o desempenho acadêmico e a competência social, este estudo teve por objetivos principais:

a) comparar a frequência de envolvimento parental, entre pais e mães;

b) investigar a relação entre a frequência de envolvimento parental, a competência social e o desempenho acadêmico de crianças escolares.

\section{Método}

\section{Participantes}

Participaram dessa pesquisa 12 pais e mães (tratavam-se de casais), de crianças da $2^{\mathrm{a}}$ série do ensino fundamental (com média de idade de 8 anos) 
e três professoras. A média de idade dos pais foi de 36,8 e das mães, de 34,5 . Os casais tinham em média dois filhos, estavam casados ou vivendo como casados há aproximadamente 13 anos e eram de classe socioeconômica baixa e média baixa. Em relação às professoras, todas são do sexo feminino, com idade média de 31,5 anos e com $3^{\circ}$ grau completo.

\section{Local da pesquisa}

A presente pesquisa foi desenvolvida em uma escola municipal, em uma cidade de pequeno porte do interior do Estado de São Paulo.

\section{Medidas avaliativas dos pais}

Os pais preencheram ao questionário "Avaliação do envolvimento parental", construído com base em instrumentos já existentes (Cia, 2005), composto por duas escalas (Likert):

a) escala de comunicação entre pais e filhos, contendo 22 itens, com a pontuação variando entre 0 (nunca) e 365 (uma vez por dia) $(\alpha=0,89)$;

b) escala de participação dos pais nas atividades escolares, culturais e de lazer do filho, contendo 19 itens, com a pontuação variando entre 0 (nunca) e 365 (uma vez por dia) $(\alpha=0,87)$.

\section{Medidas avaliativas dos professores}

Para avaliar o repertório de habilidades sociais, a existência e a intensidade dos problemas de comportamento das crianças utilizou-se o Social Skills Rating System (SSRS - Versão para professores) (Gresham \& Elliott, 1990, validado para o nosso contexto por Bandeira, Del Prette, Del Prette $\&$ Magalhães, 2009). Esse instrumento é composto por três escalas tipo Likert:

a) 30 itens, em que a professora assinala qual a frequência (nunca, algumas vezes e muito frequente) que a criança emite cada uma das situações de interação social (sendo distribuídos esses itens em cinco fatores: responsabilidade/cooperação, asserção, autocontrole, autodefesa e cooperação com pares);

b) 18 itens em que a professora assinala qual a frequência (nunca, algumas vezes e muito frequente) que a criança emite cada um dos comportamentos problema (sendo distribuídos esses itens em dois fatores: comportamentos problemáticos externalizantes e comportamentos problemáticos internalizantes);

c) nove itens em que a professora avalia o desempenho acadêmico da criança.

\section{Procedimento de coleta de dados}

Os pais e as mães receberam o questionário "Avaliação do envolvimento parental", juntamente com uma carta explicativa dos objetivos da pesquisa e dos procedimentos de coleta de dados. Os pais também receberam os Termos de Consentimento Livre e Esclarecido para autorizar sua participação. O prazo para a entrega dos questionários preenchidos pelos pais foi de duas semanas. Após a devolução, foram entregues os questionários para as professoras (SSRS - versão para professores), juntamente com o Termo de Consentimento Livre e Esclarecido, considerando apenas os alunos cujos pais e mães responderam ao questionário e consentiram com a participação na pesquisa.

\section{Procedimento de análise de dados}

Com o questionário respondido pelos pais e pelas mães, foram realizadas análises de medidas de tendência central e dispersão. Os dados do SSRS Versão para professores foram analisados com base no manual do instrumento. Com os itens que compõem escala, foram realizadas análises de consistência interna, para avaliar a fidedignidade das medidas. Para comparar os dados dos pais e das mães foram utilizados o teste- $t$, e para estabelecer relações entre a frequência de envolvimento parental, o repertório de habilidades sociais, os problemas de comportamento e o desempenho acadêmico das crianças realizou-se o teste de correlação de Pearson - SPSS. 


\section{Resultados}

Os resultados serão apresentados de forma a comparar a frequência de envolvimento materno e paterno e de relacionar a frequência de envolvimento parental com o repertório de habilidades sociais, os problemas de comportamento e o desempenho acadêmico das crianças (segundo a opinião de suas professoras). Ressalta-se que, por meio de teste de Anova e Qui-quadrado, verificou-se que não havia diferenças estatisticamente significativas entre os dados sociodemográficos dos pais e das mães.

\section{Envolvimento parental}

A Tabela 1 compara a frequência de comunicação com os filhos, entre pais e mães.

Tabela 1 - Dados descritivos dos itens da escala de comunicação pais e filhos: comparação das respostas dadas pelos pais e mães

\begin{tabular}{|c|c|c|c|c|c|c|}
\hline \multirow{2}{*}{ Item } & \multicolumn{2}{|c|}{ Mãe } & \multicolumn{2}{|c|}{ Pai } & \multicolumn{2}{|c|}{ Teste $\mathbf{t}$} \\
\hline & Média & D. P. & Média & D. P. & $\mathbf{t}$ & gl \\
\hline \multicolumn{7}{|l|}{ Sua mãe/Seu pai } \\
\hline Dá carinho a você? & 365,0 & 107,9 & 254,1 & 139,5 & $2,76^{*}$ & 22 \\
\hline Pergunta para você sobre aspectos do seu dia a dia? & 345,4 & 67,8 & 214,9 & 135,4 & $2,98 * *$ & 22 \\
\hline Pergunta para você sobre o que aconteceu na escola? & 345,4 & 67,8 & 201,8 & 122,5 & $3,55^{* *}$ & 22 \\
\hline Mantém diálogo com você? & 319,3 & 107,9 & 267,1 & 121,0 & ns & \\
\hline Elogia você? & 319,3 & 107,9 & 236,9 & 149,6 & ns & \\
\hline Impõe limites a você? & 288,9 & 140,4 & 269,3 & 145,2 & ns & \\
\hline Oferece ajuda a você, quando precisa? & 280,2 & 127,0 & 165,9 & 126,6 & $2,21 *$ & 22 \\
\hline Expressa sentimentos positivos em relação às suas atitudes? & 280,2 & 127,0 & 204,1 & 147,5 & ns & \\
\hline Pergunta para você sobre seus amigos? & 224,7 & 150,7 & 178,0 & 144,1 & ns & \\
\hline Expressa as opiniões dele a você? & 209,1 & 167,9 & 144,3 & 142,4 & ns & \\
\hline Quando promete algo a você, cumpre a promessa? & 186,9 & 148,1 & 164,4 & 165,1 & ns & \\
\hline Expressa sentimentos negativos em relação às suas atitudes? & 162,8 & 156,9 & 203,2 & 145,4 & ns & \\
\hline \multicolumn{7}{|l|}{ Você... } \\
\hline Procura conversar com seus pais? & 341,5 & 74,3 & 345,4 & 67,8 & ns & \\
\hline Solicita que seus pais façam algo para você? & 322,3 & 95,1 & 218,0 & 159,6 & ns & \\
\hline $\begin{array}{l}\text { Conta para seus pais as coisas boas ou ruins ocorridas com você em relação } \\
\text { aos amigos? }\end{array}$ & 315,0 & 120,0 & 253,0 & 166,0 & ns & \\
\hline Dá carinho (abraços, beijos) aos seus pais? & 306,3 & 106,3 & 308,5 & 132,4 & ns & \\
\hline $\begin{array}{l}\text { Conta para seus pais as coisas boas ou ruins ocorridas com você em relação } \\
\text { à escola? }\end{array}$ & 299,7 & 119,5 & 256,3 & 161,0 & ns & \\
\hline Faz perguntas para seus pais referentes ao dia a dia dele? & 247,5 & 122,7 & 230,2 & 145,8 & ns & \\
\hline Faz elogios a seus pais? & 247,5 & 122,7 & 221,3 & 155,3 & ns & \\
\hline Pede para que seus pais ajudem em alguma atividade (acadêmica ou não)? & 222,6 & 139,2 & 167,2 & 152,7 & ns & \\
\hline $\begin{array}{l}\text { Expressa desejos e preferências a seus pais, dando razão para suas ações e } \\
\text { posições? }\end{array}$ & 131,2 & 122,2 & 120,5 & 133,1 & ns & \\
\hline Desafia as regras (desobedece) de seus pais? & 108,3 & 129,6 & 119,5 & 134,1 & ns & \\
\hline Total & 262,2 & 55,7 & 200,6 & 85,8 & $2,73 *$ & 18 \\
\hline
\end{tabular}

Legenda: ${ }^{*} \mathrm{p}<0,05 ;{ }^{*} \mathrm{p}<0,01 ; \mathrm{ns}=$ não existe diferença significativa entre as médias.

Nota 1: A freqüência foi apontada usando uma escala que variou de 0 , 'nunca' 12, 'uma vez por mês' 52 , 'uma vez por semana' 104 , 'duas ou três vezes por semana' e 365 , 'todo dia'. 
Em média, a maioria das mães e dos pais relatou que usava todas as formas de comunicação com os filhos incluídas neste estudo, com uma frequência de mediana a mediana alta. Dar carinho ao filho $(\mathrm{t}(22)=2,76, \mathrm{p}<0,05)$, perguntar para o filho sobre aspectos do seu dia a dia $(\mathrm{t}(22)=2,98, \mathrm{p}<$ $0,01)$, perguntar para o filho sobre o que aconteceu na escola $(\mathrm{t}(22)=3,55 ; \mathrm{p}<0,01)$ e oferecer ajuda ao filho quando precisa $(\mathrm{t}(22)=2,21, \mathrm{p}<0,01)$ foram habilidades comunicativas que as mães disseram que realizavam com maior frequência que seus maridos. Considerando a escala como um todo, as mães se comunicavam com uma frequência estatisticamente maior que os pais: $(\mathrm{t}(18)=2,73, \mathrm{p}<0,05)$.

A Tabela 2 compara a participação nas atividades escolares, culturais e de lazer do filho, entre pais e mães.
Ao comparar pais e mães com a participação nessas atividades, pode-se verificar que há uma diferença estatisticamente significativa na média de freqüência. Os pais apresentaram maior participação do que as mães no seguinte item: "brincar com o filho" $(\mathrm{t}(22)=2,33, \mathrm{p}<0,05)$. As mães, por sua vez, participavam com uma frequência estatisticamente maior que a dos pais nas seguintes atividades: "acompanhar seu filho para se vestir" $(\mathrm{t}(20)=2,69, \mathrm{p}<$ 0,05); "auxiliar seu filho nas lições de casa" ( $t(18,2)$ $=2,18, \mathrm{p}<0,05)$.

\section{Crianças}

Os dados das crianças se referem à avaliação que as professoras fizeram sobre os problemas de

Tabela 2 - Dados descritivos dos itens de participação dos pais nas atividades escolares, culturais e de lazer do filho: comparação das respostas dadas pelos pais e mães

\begin{tabular}{|c|c|c|c|c|c|c|}
\hline \multirow{2}{*}{ Item } & \multicolumn{2}{|c|}{ Mãe } & \multicolumn{2}{|c|}{ Pai } & \multicolumn{2}{|c|}{ Teste $\mathbf{t}$} \\
\hline & Média & D. $P$. & Média & D. P. & $\mathrm{t}$ & g1 \\
\hline \multicolumn{7}{|l|}{ Sua mãe/Seu pai... } \\
\hline Incentiva você a assumir responsabilidade por tarefas escolares. & 345,4 & 67,8 & 315,0 & 120,0 & ns & \\
\hline Acompanha você nas refeições. & 345,4 & 67,8 & 273,7 & 136,9 & ns & \\
\hline Pede para você organizar objetos pessoais (roupas, brinquedos). & 345,4 & 67,8 & 270,3 & 143,2 & ns & \\
\hline Valoriza as suas conquistas acadêmicas. & 319,3 & 107,9 & 270,3 & 143,2 & ns & \\
\hline Auxilia você nas atividades de higiene (escovar os dentes, tomar banho). & 306,3 & 106,3 & 280,2 & 127,0 & ns & \\
\hline Acompanha o seu progresso escolar. & 306,3 & 106,3 & 231,2 & 144,1 & ns & \\
\hline Auxilia você nas lições de casa. & 306,3 & 106,3 & 189,5 & 145,3 & $2,18^{*}$ & 18,2 \\
\hline Acompanha você para se vestir. & 296,4 & 127,4 & 180,1 & 168,9 & $2,69 *$ & 20 \\
\hline $\begin{array}{l}\text { Incentiva você a realizar atividades domésticas (cuidar das próprias coisas, } \\
\text { da casa, etc.). }\end{array}$ & 262,8 & 153,5 & 200,8 & 172,2 & ns & \\
\hline Valoriza as suas conquistas esportivas. & 247,6 & 147,4 & 270,3 & 143,2 & ns & \\
\hline Incentiva você a ler (livros, revistas, jornais). & 224,7 & 150,7 & 220,3 & 156,8 & ns & \\
\hline Incentiva você a brincar com jogos educativos. & 214,8 & 161,0 & 150,8 & 164,4 & ns & \\
\hline Assiste filme com você da sua escolha. & 131,3 & 147,0 & 114,4 & 135,9 & ns & \\
\hline Incentiva você a ter contato com outros adultos (tios, amigos da família, etc.). & 126,6 & 149,9 & 86,7 & 98,9 & ns & \\
\hline Brinca com você. & 120,2 & 124,1 & 221,5 & 152,3 & $2,33^{*}$ & 22 \\
\hline $\begin{array}{l}\text { Incentiva você a ter contato com outras crianças (leva na casa dos amigos, } \\
\text { recebe os amigos em casa). }\end{array}$ & 88,8 & 133,9 & 91,2 & 133,0 & ns & \\
\hline Lê/Conta histórias para você. & 80,9 & 101,9 & 64,8 & 105,6 & ns & \\
\hline Passeia com você (shopping, zoológico, casa de familiares, etc.). & 62,8 & 101,9 & 67,0 & 100,2 & ns & \\
\hline Assiste eventos culturais com você (teatro, cinema, shows musicais). & 43,4 & 103,0 & 46,2 & 107,5 & ns & \\
\hline Total & 219,7 & 50,9 & 167,0 & 88,6 & ns & \\
\hline
\end{tabular}

Legenda: $*_{\mathrm{p}}<0,05 ;$ ns $=$ não existe diferença significativa entre as médias.

Nota 2: A freqüência foi apontada usando uma escala que variou de 0, 'nunca' 12 , 'uma vez por mês' 52, 'uma vez por semana' 104 , 'duas ou três vezes por semana' e 365 , 'todo dia'. 
comportamento, o repertório de habilidades sociais e o desempenho acadêmico dessas crianças. Assim, a Tabela 3 mostra a existência (ou não) de comportamentos problema, o repertório de habilidades sociais e o desempenho acadêmico das crianças, segundo a opinião das professoras.

De acordo com as professoras, os comportamentos problemáticos (internalizantes ou externalizantes) e o desempenho acadêmico de seus alunos estavam todos na média, considerando-se a amostra de referência (Bandeira et al., 2009). Em relação aos fatores responsabilidade/cooperação, asserção positiva, autodefesa e cooperação com os pares, as crianças também apresentaram frequência mediana. Já na habilidade de autocontrole, as crianças apresentaram referências acima da média.

Tabela 3 - Pontuação média das medidas de problemas de comportamento, do repertório de habilidades sociais e do desempenho acadêmico das crianças, segundo as professoras

\begin{tabular}{lcc}
\hline & Média & D.P. \\
\hline Comportamentos problemáticos internalizantes & 1,2 & 1,8 \\
Comportamentos problemáticos externalizantes & 0,9 & 1,1 \\
Comportamentos problemáticos total & 2,6 & 3,1 \\
F1 = Responsabilidade/Cooperação & 27,3 & 2,1 \\
F2 = Asserção Positiva & 14,7 & 2,5 \\
F3 = Autocontrole & 17,2 & 6,8 \\
F4 = Autodefesa & 4,7 & 1,2 \\
F5 = Cooperação com pares & 6,2 & 1,4 \\
Repertório de habilidades sociais total & 53,5 & 9,7 \\
Desempenho acadêmico & 39,5 & 5,58 \\
\hline
\end{tabular}

Legenda: CPI (média professores =0,00-3,24); CPE (média professores =0,25-7,85); CPT (média professores = 0,87-8,97). F1 = Responsabilidade/Cooperação (média = 15,35-28,61); F2 = Asserção Positiva (média = 6,86-15,22); F3 = Autocontrole (média $=8,34-16,20) ; \mathrm{F} 4=$ Autodefesa (média $=1,67-5,11) ; \mathrm{F} 5=$ Cooperação com pares (média = 2,61-6,69) e Total (média $=28,73-51,83)$.

Desempenho acadêmico $=$ Pontuação máxima $=45($ Escore médio $=27,72-42,42)$.

\section{Relaçáo entre as variáveis parentais e infantis}

A Tabela 4 mostra as relações entre a frequência de envolvimento paterno e materno com os problemas de comportamento, o repertório de habilidades sociais e o desempenho acadêmico das crianças.

Como mostram os dados da tabela, quanto maior a frequência da participação dos pais nas atividades escolares, culturais e de lazer dos filhos, maior o desempenho acadêmico das crianças, segundo as professoras. Esse, por sua vez, estava positivamente correlacionado com o repertório de habilidades sociais das crianças. Além disso, quanto maior a frequência da participação das mães nas atividades escolares, culturais e de lazer dos filhos, menor o índice de problemas de comportamento externalizantes e maior o repertório de habilidades sociais das crianças. A comunicação entre mãe e filho também estava positivamente correlacionada com o repertório de habilidades sociais das crianças.

\section{Discussão}

Por meio do presente trabalho foi possível verificar que pais e mães usavam várias formas de comunicação para com seus filhos, além de se comunicarem com alta frequência com eles. Tais resultados vêm a demonstrar que os homens dessa amostra estão mais envolvidos nas atividades familiares do que ocorria em gerações anteriores, mostrando uma 
Tabela 4 - Correlações significativas entre as variáveis parentais e infantis

\begin{tabular}{|c|c|c|c|c|c|c|c|}
\hline & CPE & F1 & F2 & F3 & F4 & $\begin{array}{l}\text { Repertório de } \\
\text { habilidades } \\
\text { sociais total }\end{array}$ & $\begin{array}{c}\text { Desempenho } \\
\text { acadêmico }\end{array}$ \\
\hline $\begin{array}{l}\text { Participação dos pais nas atividades } \\
\text { escolares, culturais e de lazer dos } \\
\text { filhos, segundo os pais }\end{array}$ & $0,633^{*}$ & ns & ns & ns & ns & ns & $0,681^{*}$ \\
\hline Comunicação entre mães e filhos & ns & ns & ns & ns & ns & $0,643^{*}$ & ns \\
\hline $\begin{array}{l}\text { Participação das mães nas atividades } \\
\text { escolares, culturais e de lazer dos } \\
\text { filhos }\end{array}$ & $-0,819 * *$ & $0,616^{*}$ & $0,694 *$ & ns & $0,578+$ & $0,732 * *$ & ns \\
\hline Desempenho acadêmico & $-0,659 *$ & $0,623 *$ & ns & $0,643^{*}$ & $0,627^{*}$ & $0,744 * *$ & ns \\
\hline
\end{tabular}

Nota: $+\mathrm{p}<0,1 ;{ }^{*} \mathrm{p}<0,05 ;{ }^{* *} \mathrm{p}<0,01 \mathrm{~ns}=$ não apresenta diferenças estatisticamente significativas.

postura da "nova paternidade". A cultura interfere muito no que diz respeito à educação e envolvimento dos pais para com seus filhos. Na nossa sociedade, as mulheres são educadas para cuidar dos filhos e da casa, enquanto que dos homens espera-se que cumpram o papel de provedor financeiro. Porém, com a inserção das mulheres no mercado de trabalho, os homens passaram a participar mais do cotidiano de seus filhos, envolvendo-se mais em certas atividades, uma vez que as mulheres passaram a precisar mais dessa participação masculina, além de "permitirem" esse maior envolvimento paterno (Bertolini, 2002; Brandth \& Kvande, 2002; Cabrera et al., 2000; Tiedje, 2004). Tal envolvimento torna-se um fator de proteção para o desenvolvimento da criança, para além do envolvimento materno, pois vários estudos apontam que a participação dos pais (homens) nas atividades dos filhos interfere diretamente no desenvolvimento socioemocional e no desempenho acadêmico das crianças (Atzaba-Poria, Pike \& Deater-Deckard, 2004; Cia, 2009; Cia et al., 2004, 2006; Hong \& Ho, 2005).

As mães apresentaram frequência estatisticamente maior que os homens no que se refere a dar carinho aos filhos, perguntar aos filhos sobre aspectos do dia a dia, sobre o que aconteceu na escola. Os pais devem mostrar interesse pelo cotidiano da criança, demonstrar que suas atividades são tão importantes quanto as deles e que estão dispostos a ouvir seus problemas e ajudá-los a resolvê-los. Esse estilo de educar, em contraposição com os estilos punitivos ou coercitivos (Alvarenga \& Piccinini, 2001), traz consequências positivas para o desenvolvimento socioemocional das crianças, pois elas se sentem amadas por seus pais e a relação entre pais e filhos torna-se de confiança, ou seja, a criança sabe que se cometer algum erro, terá espaço para refletir e dialogar sobre aquilo (Gomide, 2008).

$\mathrm{Na}$ escala referente à participação dos pais e das mães nas atividades escolares, culturais e de lazer dos filhos, as mães mostraram acompanhá-los mais nos momentos de se vestir e auxiliá-los mais nas lições de casa do que os pais. Já no item brincar com o filho, os pais apresentavam frequência significativamente maior que as mães. Isso vem demonstrar que possivelmente existe uma divisão de tarefas entre os pais e as mães, com elas sendo mais responsáveis pelos cuidados e pela educação dos filhos, e os pais, pelas atividades de lazer (Bertolini, 2002; Cia, Pereira, Del Prette \& Del Prette, 2006; Lewis \& Dessen, 1999).

Os pais e as mães que realizam com maior frequência as atividades escolares, culturais e de lazer com os filhos são os que apresentam maior comunicação com os filhos. Isso é indicativo de que pais e mães precisam dialogar com eles e questioná-los sobre temas de seu interesse, para que eles permitam esse maior envolvimento parental.

Em relação à avaliação das professoras, as crianças estão com o índice de problemas de comportamento na média e com bom repertório de habilidades sociais. Além disso, o desempenho acadêmico e o repertório de habilidades sociais estão positivamente correlacionados. Esse dado é importante porque as crianças que participaram deste estudo estão em fase de transição, momento em que lhes são exigidas novas habilidades (Aspesi, Dessen \& Chagas, 2005; Marturano, 2004, 2008), e um bom desempenho 
acadêmico e desenvolvimento social torna-se um fator protetivo para o seu desenvolvimento.

No entanto, quando os pais (homens) participavam ativamente das atividades culturais, escolares e de lazer dos filhos, a probabilidade de a criança apresentar problemas de comportamentos externalizantes era maior. Os homens, de maneira geral, exibem mais comportamentos agressivos do que as mulheres e provavelmente estão sendo modelo para os filhos, como mostrado em outros estudos realizados em nosso contexto (Cia et al., 2006). Ressalta-se que essas crianças podem vir a ser rejeitadas pelos seus pares, pois podem generalizar esse modelo agressivo para outros ambientes, como o escolar (Marinho, 2003; Sisto, 2005).

Em contrapartida, quanto maior a frequência de participação dos pais nas atividades dos filhos, melhor o desempenho acadêmico dos filhos. Estudos mostram que os pais realizam mais atividades lúdicas e recreativas com os filhos, o que vem a influenciar diretamente no desenvolvimento cognitivo deles (Cia, Pamplin \& Williams, 2008; Flouri \& Buchanan, 2003).

Considerando o papel materno, quanto maior a frequência de participação das mães nas atividades escolares, culturais e de lazer dos filhos e quanto maior a frequência de comunicação com o filho, melhor o repertório de habilidades sociais das crianças. Além disso, quanto maior a frequência de participação nas atividades escolares, culturais e de lazer dos filhos, menos problemas de comportamento externalizantes foram apresentados pelas crianças. Nesse sentido, as mães estão sendo importantes agentes socializadores e modelo de conduta dos filhos, corroborando com os dados de outros estudos (Costa, Cia \& Barham, 2007; Ferreira \& Marturano, 2002).

No presente estudo, a adesão das professoras foi pequena. Pode-se levantar a hipótese de que, se essa participação tivesse sido maior, poderiam ter sido feitas mais relações, ou seja, comparações entre a participação dos pais e o desempenho acadêmico das crianças, assim como seus comportamentos com seus pares no contexto escolar. Pode-se dizer ainda que este trabalho pode ter continuidade com um número maior de professoras.

\section{Consideraçóes finais}

O objetivo deste estudo foi relacionar o envolvimento parental com o desempenho acadêmico e o repertório de habilidades sociais apresentado pelas crianças. O trabalho confirma dados da literatura quanto à importância do envolvimento parental sobre o desenvolvimento social e o desempenho acadêmico dos filhos. Dessa forma, nota-se a necessidade de intervir com pais e mães para que eles conheçam as muitas ações que podem melhorar o seu envolvimento enquanto pais. Ressalta-se que vários estudos apontam para ganhos positivos no desenvolvimento de filhos cujos pais ou mães participaram de intervenções educativas (Barros \& Del Prette, 2007; Bolsoni-Silva, Salina-Brandão, Rosin-Pinola \& Versuti-Stoque, 2008; Cia, 2009; Duch, 2005; Pinheiro, Haase, Del Prette, Amarante \& Del Prette, 2006).

Como limitações do estudo, tem-se que este foi realizado em apenas duas escolas, em que as características sociodemográficas dos participantes são similares, diminuindo a possibilidade de generalização. Além disso, a adesão dos professores não foi de $100 \%$, o que pode ter influenciado na baixa correlação ou na inexistência de relações entre as variáveis, pelo baixo número de participantes. Apesar dessas limitações, o estudo aponta para diretrizes de intervenções com pais, uma vez que mostrou alguns comportamentos tidos como facilitadores do desempenho acadêmico e do desenvolvimento social das crianças.

Destaca-se que outros estudos similares poderiam ser realizados, por exemplo:

a) com maior número de alunos e professores;

b) com diferentes faixas etárias;

c) compararcriançasquemoramcomos pais biológicos e de famílias reconstituídas;

d) em diferentes escolas e com a população de diferentes níveis socioeconômicos, para aumentar a generalização dos resultados.

\section{Referências}

Alvarenga, P., \& Piccinini, C. (2001). Práticas educativas materna e problemas de comportamento em pré-escolares. Psicologia: Reflexão e Crítica, 14(3), 449-460.

Anselmi, L., Piccinini, C. A., Barros, F. C., \& Lopes, R. S. (2004). Psychosocial determinants of behavior problems in Brazilian preschool children. Journal of Child Psychology and Psychiatry, 45(4), 779-788. 
Aspesi, C. C., Dessen, M. A., \& Chagas, J. F. (2005). A ciência do desenvolvimento humano: Uma perspectiva interdisciplinar. In M. A. Dessen \& A. L. C. Costa (Org.). A ciência do desenvolvimento humano: Tendências atuais e perspectivas futuras (pp. 19-36). Porto Alegre: Artmed.

Atzaba-Poria, N., Pike, A., \& Deater-Deckard, K. D. (2004). Do risk factors for problem behavior act in a cumulative manner? An examination of ethnic minority and majority children through an ecological perspective. Journal of Child Psychology and Psychiatry, 45(4), 707-718.

Bandeira, M., Del Prette, Z. A. P., Del Prette, A., \& Magalhães, T. (2009). Validação das escalas de habilidades sociais, comportamentos problemáticos e competência acadêmica (SSRS-BR) para o ensino fundamental. Psicologia: Teoria e Pesquisa, 25(2), 271-282.

Bandeira, M., Rocha, S. S., Souza, T. M. P., Del Prette, Z. A. P., \& Del Prette, A. (2006). Comportamentos problemáticos em estudantes do ensino fundamental: Características da ocorrência e relação com habilidades sociais e dificuldades de aprendizagem. Estudos de Psicologia, 11(2), 199-208.

Barros, S. K. S.N., \& DelPrette, A. (2007). Um treinamento de habilidades sociais para pais pode beneficiar os filhos na escola? Revista da Sociedade e Psicologia do Triângulo Mineiro, 11(1), 107-123.

Bertolini, L. B. A. (2002). Funções paternas, maternas e conjugais naSociedade Ocidental. In L. B. A. Bertoline (Org.). Relações entre o trabalho da mulher e a dinâmica familiar (pp. 27-31). São Paulo: Vetor.

Bolsoni-Silva, A. T., Del Prette, A., \& Del Prette, Z. A. P. (2000). Relacionamento pais- filhos: Um programa de desenvolvimento interpessoal em grupo. Psicologia Escolar e Educacional, 3(3), 203-215.

Bolsoni-Silva, A. T., Salina-Brandão, A., Rosin-Pinola, A. R. \& Versuti-Stoque, F. M. (2008). Avaliação de um programa de intervenção de habilidades sociais educativas parentais: Um estudo-piloto. Psicologia: Ciência e Profissão, 28(1), 18-33.

Brandth, B., \& Kvande, E. (2002). Reflexive fathers: Negotiating parental leave and working life. Gender, Work and Organization, 9(2), 186-203.
Cabrera, N. J., Tames-Lemonda, C., Bradley, R. H., Hofferth, S., \& Lamb, M. E. (2000). Fatherhood in the twenty first century. Child Development, 71(1), 127-136.

Carlson, M. J. (2006). Family structure, father involvement, and adolescence behavioral outcomes. Journal of Marriage and Family, 68(1), 137-154.

Cia, F. (2005). O impacto do turno de trabalho do pai no desempenho acadêmico e no autoconceito de crianças escolares. Dissertação de Mestrado não publicada, Programa de Pós-Graduação em Educação Especial, Universidade Federal de São Carlos, São Carlos, São Paulo.

Cia, F. (2009). Um programa para aprimorar o envolvimento paterno: Impactos no desenvolvimento do filho. Tese de Doutorado não publicada, Programa de Pós-Graduação em Educação Especial, Universidade Federal de São Carlos, São Carlos, São Paulo.

Cia, F., D’Affonseca, S. M., \& Barham, E. J. (2004). A relação entre envolvimento paterno e desempenho acadêmico dos filhos. Paidéia: Cadernos de Psicologia e Educação, 14(29), 277-286.

Cia, F., Pamplin, R. C. O., \& Del Prette, Z. A. P. (2006). Comunicação e participação Pais-filhos: Correlação com habilidades sociais e problemas de comportamento dos filhos. Paidéia, 16(35), 395-406.

Cia, F., Pamplin, R. C. O., \& Williams, L. C. A. (2008). O impacto do envolvimento parental no desempenho acadêmico de crianças escolares. Psicologia em Estudo, 13(2), 351-360.

Cia, F., Pereira, C. S., Del Prette, Z. A. P., \& Del Prette, A. (2006). Habilidades sociais parentais e o relacionamento entre pais e filhos. Psicologia em Estudo, 11(1), 73-81.

Cia, F., Williams, L., \& Aiello, A. L. R. (2005). Influências paternas no desenvolvimento infantil: Revisão de literatura. Revista Psicologia Escolar e Educacional, 9(2), 225-233.

Coley, R. L., Morris, J. E., \& Hernandez, D. (2004). Outof-school care and problem behavior trajectories among low-income adolescents: Individual, family, and neighborhood characteristics as adds risks. Child Development, 73(3), 948-965. 
Costa, C. S., Cia, F., \& Barham, E. J. (2007). Envolvimento materno e desempenho acadêmico: Comparando crianças residindo com as mães e com ambos os pais. Revista Brasileira de Psicologia Escolar e Educacional, 11(2), 339-351.

Cozby, P. C. (2006). Métodos de pesquisa em ciências do comportamento. São Paulo: Atlas.

Davidov, M., \& Grusec, J. E. (2006). Untangling the links of parental responsiveness to distress and warmth to child outcomes. Child Development, 77(1), 44-58.

Del Prette, Z. A. P., \& Del Prette A. (2005). Psicologia das habilidades sociais na infância - Teoria e prática. Petrópolis: Vozes.

Diniz, G. (2004). Homens e mulheres frente à interação casamento trabalho: Aspectos da realidade brasileira. In T. Féres-Carneiro (Org.). Casal e família: Entre a tradição e a transformação (pp. 31-44). Rio de Janeiro: NAU.

Duch, H. (2005). Redefining parent involvement in Head Start: A two-generation approach. Early Child Development and Care, 175(1), 23-35.

Dunn, J. (2004). Annotation: Children's relationships with their nonresident father. Journal of Child Psychology and Psychiatry, 45(4), 659-671.

Ferreira, M. C. T., \& Marturano, E. M. (2002). Ambiente familiar e os problemas do comportamento apresentados por crianças com baixo desempenho escolar. Psicologia: Reflexão e Crítica, 15(1), 35-44.

Flouri, E., \& Buchanan, A. (2003). The role of father involvement in children's later mental health. Journal of Adolescence, 26, 63-78.

Gomide, P. I. C. (2008). Pais presentes pais ausentes: Regras e limites. Petrópolis: Vozes.

Gresham, F. M., \& Elliott, S. N. (1990). Social skills rating system. Circle Pines, $\mathrm{MN}$ : American Guidance Service, Inc.

Hong, S., \& Ho, H. (2005). Direct and indirect longitudinal effects of parental involvement on student achievement: Second-order latent growth modeling across ethnic groups. Journal of Educational Psychology, 97(1), 32-42.
Lansford, J. E., Criss, M. M., Pettit, G. S., Dodge, K. A., \& Bates, J. E. (2003). Friendship quality, peer group affiliation, and peer antisocial behavior as moderators of the link between negative parenting and adolescent externalizing behavior. Journal of Research on Adolescence, 13(2), 161-184.

Lewis, C., \& Dessen, M. A. (1999). O pai no contexto familiar. Psicologia: Teoria e Pesquisa, 15(1), 9-16.

Lindsey, E. W., Caldera, Y. M., \& Iankersley, L. (2009). Marital conflict and the quality of young children's peer play behavior: The mediating and moderating role of parent-child emotional reciprocity and attachmentsecurity. Journal of Family Psychology, 23(2), 130-145.

Marinho, M. L. C. (2003). Comportamento anti-social infantil: Questões teóricas e de Pesquisa. In A. Del Prette \& Z. A. P. Del Prette (Org.). Habilidades sociais, desenvolvimento e aprendizagem: Questões conceituais, avaliação e intervenção (pp. 61-83). Campinas: Alínea.

Marturano, E. M. (2004). Fatores de risco e proteção no desenvolvimento sócio-emocional de crianças com dificuldades de aprendizagem. In E. G. Mendes, M. A. Almeida, \& L. C. A. Williams (Org.). Avanços recentes em Educação Especial (pp.159-165). São Carlos: EDUFSCar.

Marturano, E. M. (2008). Tensões cotidianas na transição da primeira série: Um enfoque de desenvolvimento. Psicologia em Estudo, 13(1), 79-87.

Marturano, E. M., \& Loureiro, S. R. O. (2003). Desenvolvimento socioemocional e as queixas escolares. In A. Del Prette \& Z. A. P. Del Prette (Org.). Habilidades sociais, desenvolvimento e aprendizagem: Questões conceituais, avaliação e intervenção (pp. 259-291). Campinas: Alínea.

Mackinnon-Lewis, C., Castellino, D. R., Brody, G. H., \& Fincham, F.D. (2001). A longitudinal examination of the associations between father's and children's attributions and interactions. Social Development, 10(4), 473-487.

Newman, K., Harrison, L., Dashiff, C., \& Daviesm, S. (2008). Relationships between parenting styles and risk behaviors in adolescent health: An integrative literature review. Revista Latino Americana de Enfermagem, 16(1), 142-150. 
Pamplim, R. (2005). A interface família-escola na inclusão da criança com necessidades educacionais especiais. Dissertação de Mestrado não publicada, Programa de Pós-Graduação em Educação Especial, Universidade Federal de São Carlos, São Carlos.

Patterson, J., Mockford, C., \& Stewart-Brow, S. (2005). Parents' perceptions of the value of the WebsterStratton Parenting Programme: A qualitative study of a general practice based initiative. Child: Care, Health and Development, 31(1), 53-64.

Pinheiro, M. I. S., Haase, V. G., Del Prette, A., Amarante, C. L. D., \& Del Prette, Z. A. P. (2006). Treinamento de habilidades sociais educativas para pais de crianças com problemas de comportamento. Psicologia: Reflexão e Crítica, 19(3), 1-15.

Sisto, F. F. (2005). Aceitação-rejeição para estudar e agressividade na escola. Psicologia em Estudo, 10(1), 117-125.

Szelbracikowski, A. C., \& Dessen, M. A. (2007). Problemas de comportamento exteriorizado e as relações familiares: Revisão de literatura. Psicologia em Estudo, 12(1), 33-40.

Tiedje, L. B. (2004). Process of change in work/home incompatibilities employed mothers. Journal of Social Issues, 60(4), 787-800.

Recebido: 14/07/2010

Received: 07/14/2010

Aprovado: $12 / 09 / 2010$

Approved: 09/12/2010 